\title{
ANÁLISE ERGONÔMICA DO AMBIENTE DE TRABALHO NA FABRICAÇ̃̃O DE FERRAMENTAS FLORESTAIS
}

\section{ERGONOMIC ANALYSIS OF THE ENVIRONMENT WORKING IN THE PRODUCTION OF TOOL FORESTS}

\author{
Pompeu Paes Guimarães ${ }^{1}$ Nilton César Fiedler ${ }^{2}$ José Tarcísio da Silva Oliveira ${ }^{2}$ Ângelo Marcio \\ Pinto Leite ${ }^{3}$ Julião Soares de Souza Lima ${ }^{4}$
}

\begin{abstract}
RESUMO
Esta pesquisa objetivou avaliar o ambiente de trabalho em uma fábrica de produção de ferramentas. Este processo envolve as atividades de corte, orvado, viragem, forjadora, têmpera, inserção de cabos, esmeril, envernizamento e soldagem. Para avaliar o conforto térmico foi utilizado o IBUTG, para medir a velocidade do vento o anemômetro, luxímetro para avaliar a luminosidade e decibelímetro para analisar a exposição dos trabalhadores ao ruído. Os dados de IBUTG variaram em média de $20,9^{\circ} \mathrm{C}$ a $27,3^{\circ} \mathrm{C}$. A forjadora apresentou os maiores valores de IBUTG em média durante todo o processo produtivo. Todas as atividades apresentaram velocidade do vento abaixo de $0,75 \mathrm{~m} / \mathrm{s}$, sendo aceitável para a jornada de trabalho. A iluminância, em média oscilou de 42,9 lux a 393,3 lux. As atividades de envernizamento, têmpera, forjadora e inserção de cabos apresentaram médias de iluminância abaixo dos 150 lux necessários durante toda a jornada de trabalho. Todas as atividades apresentaram ruídos acima de $85 \mathrm{~dB}(\mathrm{~A})$, exceto o envernizamento e o corte. Os níveis de ruído variaram em média de 79,7 dB(A) no envernizamento às 8 h a $95,7 \mathrm{~dB}(\mathrm{~A})$ no esmeril às $13 \mathrm{~h}$.
\end{abstract}

Palavras-chave: ergonomia; conforto térmico; iluminância; ventilação e ruído.

\begin{abstract}
This research aimed to evaluate the work environment in a tool manufacturing factory. This process involves the cutting activities, orvado, turning, forger, temper, cable insertion, grinding, welding and varnishing. To evaluate the thermal comfort was used IBUTG to measure the wind speed anemometer, lux meter to evaluate the brightness and decibel meter to analyse the exposure of workers to noise. The data ranged IBUTG on average $20.9^{\circ} \mathrm{C}$ at $27.3^{\circ} \mathrm{C}$. The forger had the highest IBUTG values averaged over the entire production process. All activities had wind speeds below $0.75 \mathrm{~m} / \mathrm{s}$, being perfectly acceptable for the entire workday. The average luminance oscillated from 42.9 lux to 393.3 lux. The activities of varnish, temper, forger and cable insertion had average illuminance below 150 lux required throughout the workday. All activities presented noise above $85 \mathrm{~dB}(\mathrm{~A})$, except the varnishing and cutting. Noise levels ranged on average of $79.7 \mathrm{~dB}(\mathrm{~A})$ in varnishing at 8 hours $95.7 \mathrm{~dB}(\mathrm{~A})$, in the grinding at 13 hours.
\end{abstract}

Keywords: ergonomics; thermal comfort; lighting; ventilation; and noise.

1 Engenheiro Florestal, Dr., Professor do Centro de Ciências Agrárias, Departamento de Ciências Agronômicas e Florestais, Universidade Federal Rural do Semi-Árido, Av. Francisco Mota, 572, Bairro Costa e Silva, Campus Mossoró, CEP 59625-900, Mossoró (RN), Brasil. pompeu.guimaraes@ufersa.edu.br

2 Engenheiro Florestal, Dr., Professor do Departamento de Ciências Florestais e da Madeira, Universidade Federal do Espírito Santo, Av. Gov. Lindemberg, 316, Centro, Jerônimo Monteiro (ES), Brasil. nilton.fiedler@ufes.br/ jtsilva@npd.ufes.br

3 Engenheiro Florestal, Dr. Professor do Departamento de Engenharia Florestal, Universidade Federal dos Vales do Jequitinhonha e Mucuri, Rodovia MTG 367, Km 583, 5000, Alto da Jacuba, Diamantina (MG), Brasil. ampleite@ ig.com.br

4 Engenheiro Agrônomo, Dr. Professor do Departamento de Engenharia Rural, Universidade Federal do Espírito Santo. Alto Universitário, s/n, Guararema, Alegre (ES), Brasil. limajss@yahoo.com.br

Recebido para publicação em 27/07/2011 e aceito em 18/01/2018

Ci. Fl., v. 28, n. 4, out. - dez., 2018 


\section{INTRODUÇÃO}

No processo de fabricação, várias ferramentas utilizadas no setor florestal são confeccionadas por intermédio do processo de forjamento por martelamento. Esse processo é constituído por golpes ou batidas sucessivas rápidas no metal, aplicando pressão sobre as peças no momento em que existe o contato do martelo da forjadora e a peça metálica.

Se considerar tanto a diversidade de atividades quanto a diversidade humana, pode-se entender que as características do ambiente podem dificultar ou facilitar a realização das atividades. Quando um ambiente físico responde às necessidades dos usuários tanto em termos funcionais, físico/cognitivos, quanto formais, psicológicos, certamente terá um impacto positivo na realização das atividades (VILAROUCO; ANDRETO, 2008).

Deve-se entender como algumas variáveis interagem para compor o ambiente de trabalho em que a atividade vai se proceder, como a ventilação, o conforto térmico, a iluminação e o ruído a que os trabalhadores estarão expostos. Considerando-se o meio físico de trabalho, em análises ergonômicas, quando as variáveis do ambiente de trabalho excedem certos limites, podem causar desconfortos e doenças aos trabalhadores (DUTRA; LEITE; MASSAD, 2012).

Dentre estes, conforto térmico é quando a quantidade de calor recebida pelo corpo equivale à mesma quantidade de calor perdido, constituindo o equilíbrio térmico (IIDA, 2016). O Índice de bulbo úmido termômetro de globo - IBUTG - funciona como um indicador de conforto térmico que engloba os principais fatores causadores da sobrecarga térmica - alta temperatura, metabolismo, calor radiante e alta umidade relativa do ar - e, também, os principais fatores atenuadores da mesma, como a ventilação do ambiente, a baixa umidade relativa do ar e a baixa temperatura, fornecendo uma escala de tempo de trabalho e de tempo de repouso para aquela situação (COUTO, 1995).

A ventilação é um aspecto importante do conforto térmico. Ajuda a remover, por convecção, o calor gerado pelo corpo. Ao remover o ar saturado próximo da pele, facilita a evaporação do suor e o resfriamento do corpo. Em ambientes industriais, a ventilação pode ter o objetivo principal de remover o ar contaminado de aerodispersoides. Nesse caso, pode ser benéfico ou prejudicial ao conforto, dependendo da temperatura do ar (IIDA, 2016).

Segundo a NR-17, em todos os locais de trabalho deve haver iluminação adequada, natural ou artificial, geral ou suplementar, apropriada à natureza da atividade. A iluminação geral deve ser uniformemente distribuída e difusa (SEGURANÇA..., 2012). Em um ambiente industrial a localização dos equipamentos, bem como o sequenciamento lógico de produção e os níveis adequados de iluminância dentro de cada tarefa favorecem o ambiente de trabalho, promovendo motivação e qualidade de vida para $o$ trabalhador (FIEDLER et al., 2009b).

O ruído está presente em todas as fábricas que utilizam máquinas rotativas, onde as ondas sonoras geradas provocam desconforto aos ouvidos dos trabalhadores (FILIPE et al., 2014). Ao avaliar o ambiente industrial de processamento secundário de madeira, Fiedler et al. (2009a) concluíram que independentemente do tipo de madeira trabalhada em diferentes máquinas utilizadas, o ruído médio produzido foi superior ao permitido para uma jornada de trabalho.

O objetivo desta pesquisa foi analisar ergonomicamente o ambiente de trabalho na fabricação de ferramentas florestais em relação ao conforto térmico da atividade, a ventilação do ambiente, a iluminância dos postos de trabalho e aos níveis de ruído que os trabalhadores estão expostos.

\section{MATERIAL E MÉTODOS}

\section{Região de estudo}

Os dados da pesquisa foram coletados entre os meses de janeiro a março de 2011 no galpão de produção de uma empresa fabricante de ferramentas florestais, que se localiza na região montanhosa do

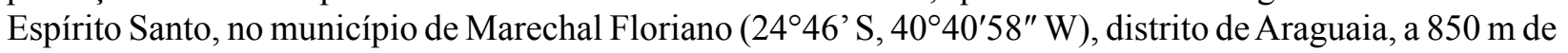


altitude. A precipitação média no município de Marechal Floriano é de $1.572,2 \mathrm{~mm}$. O clima predominante é o tropical de altitude e com temperatura média de $17,5^{\circ} \mathrm{C}$, máxima de $32^{\circ} \mathrm{C}$ e mínima de $3^{\circ} \mathrm{C}$ (AGÊNCIA NACIONAL DE ÁGUAS, 2010).

\section{Descrição dos postos de trabalho}

As ferramentas são produzidas com uso de matéria-prima feita de barras de aço de carbono. Ao todo são confeccionadas 39 modelos diferentes de ferramentas.

As avaliações foram feitas nos postos de trabalho durante o processo de produção das ferramentas da empresa (Tabela 1).

TABELA 1: Atividades que compõem o processo de produção de ferramentas.

TABLE 1: Activities that make up the production process tools.

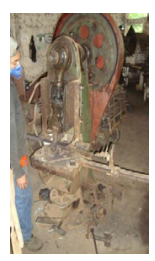

(C1)

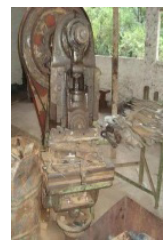

$(\mathrm{C} 2)$

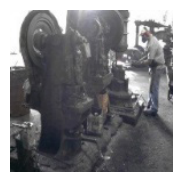

(OR)

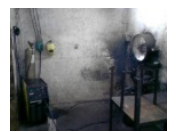

(SO)

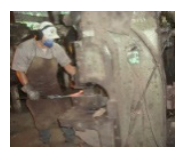

(YI)
Corte 1 - O operador mede a barra de aço e a secciona, com o uso da máquina de corte. A lâmina de corte da máquina fica perpendicular à barra de aço e serve para reduzir o comprimento da barra de aço para o tamanho correto da ferramenta.

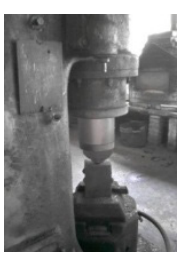

(F1)

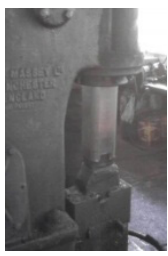

(F2)

Corte 2 - $\mathrm{O}$ operador mede a barra de aço e a secciona, com o uso da máquina de corte. A lâmina de corte da máquina fica paralela à barra de aço e serve para reduzir a largura da lâmina de aço para o tamanho correto da ferramenta.

Orvado - A extremidade da barra de aço adquire formato cilíndrico para encaixe do cabo da ferramenta. A barra de aço é aquecida e prensada de forma que fique cilíndrica.

Soldagem - Visa à união localizada de materiais de forma permanente. A soldagem é utilizada para unir a superfície cilíndrica da peça feita na região do orvado.
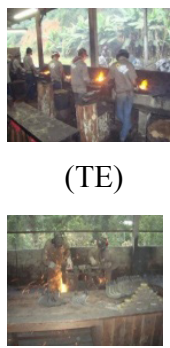

(ES)

Viragem - Fazer superfícies curvas no maior comprimento da barra de aço (Ex.: angulação da foice).

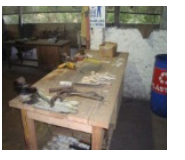

(IC)
Forjadora 1 - Aplicação de pressão sobre a peça por pancadas sucessivas. Utilizadas para alongar (esticar) as dimensões da barra de aço em seu comprimento.
Forjadora 2 - Pancadas sucessivas aplicam pressão sobre as peças para fazer um melhor acabamento de sua superfície (alisamento).

Têmpera - Ferramentas aquecidas em fornos e imersas em banho de óleo frio, potencializando a durabilidade e resistência à superfície de corte.

Esmeril - Máquina utilizada para afiar as lâminas das ferramentas.

Inserção de cabos - Fase em que é acrescida a lâmina de corte (faca, facão e cutelo) à superfície para pega.

Envernizamento - Mesa de acabamento final, na qual as peças são envernizadas e é afixado o emblema da empresa. 
Normalmente, a sequência de produção é a seguinte: corte 1, corte 2, orvado, soldagem, viragem, forjadora 1, forjadora 2, esmeril (afiação), têmpera, esmeril (acabamento), inserção de cabos (cutelo, facas e facão) e envernizamento.

\section{Conforto térmico}

As condições climáticas do ambiente de trabalho foram avaliadas com o uso de um termômetro digital de globo. Pela NR-15, anexo 3, a exposição ao calor foi avaliada com base no Índice de Bulbo Úmido Termômetro de Globo - IBUTG, definido para ambientes sem carga solar, como apresentado na Equação 1:

$$
I B U T G=0,7 t b n+0,3 t g
$$

Em que: $t b n=$ temperatura de bulbo úmido natural e $t g=$ temperatura de globo.

As medições foram efetuadas de hora em hora nas atividades de produção de ferramentas no local em que permanece o trabalhador das 8 às 17 horas. Os valores obtidos foram anotados em planilhas e, posteriormente, comparados com os valores máximos permitidos pela legislação (NR 15), apresentados na Tabela 2.

TABELA 2: Regime de trabalho permitido em função do tipo de atividade.

TABLE 2: Scheme of work due to the type of activity.

\begin{tabular}{|c|c|c|c|}
\hline \multirow{2}{*}{$\begin{array}{l}\text { Regime de trabalho intermitente com descanso no próprio } \\
\text { local de trabalho (por hora) }\end{array}$} & \multicolumn{3}{|c|}{ Tipo de atividade } \\
\hline & Leve & Moderada & Pesada \\
\hline Trabalho contínuo & até 30,0 & até 26,7 & até 25,0 \\
\hline $\begin{array}{l}45 \text { minutos trabalho } \\
15 \text { minutos descanso }\end{array}$ & 30,1 a 30,5 & 26,8 a 28,0 & 25,1 a 25,9 \\
\hline $\begin{array}{l}30 \text { minutos trabalho } \\
30 \text { minutos descanso }\end{array}$ & 30,7 a 31,4 & 28,1 a 29,4 & 26,0 a 27,9 \\
\hline $\begin{array}{l}15 \text { minutos trabalho } \\
45 \text { minutos descanso }\end{array}$ & 31,5 a 32,2 & 29,5 a 31,1 & 28,0 a 30,0 \\
\hline $\begin{array}{l}\text { O trabalho não é permitido, sem a adoção de medidas } \\
\text { adequadas de controle }\end{array}$ & acima de 32,2 & acima de 31,1 & $\begin{array}{l}\text { acima de } \\
30,0\end{array}$ \\
\hline
\end{tabular}

Fonte: Norma Regulamentadora: NR 15 (2012).

\section{Ventilação}

Os dados de ventilação foram medidos a cada hora nos postos de trabalho especificados. Foi utilizado um anemômetro digital para medir a velocidade do vento em cada atividade do processo de produção de ferramentas (Figura 1). Segundo a NR-17 (NORMA REGULAMENTADORA: NR 17, 2007), para atividades leves, a velocidade máxima do vento deve ser de $0,75 \mathrm{~m} / \mathrm{s}$.

\section{Iluminância}

A iluminância foi avaliada por meio de um luxímetro digital portátil (Figura 1). As medições foram feitas sistematicamente a cada hora nas atividades de produção de ferramentas, na altura da bancada em cada posto de trabalho, sendo utilizadas planilhas previamente elaboradas para a obtenção dos dados.

A ABNT NBR ISO 8995 (2013) trouxe novos requisitos de qualidade de sistemas de iluminação, porém, manteve o nível mínimo de iluminação mantido na ABNT NBR 5413 (1992), sendo utilizados, como pa- 
drão, para usinas de aço que trabalham com forjadoras e salas de máquinas é necessário uma iluminação entre 150 e 300 lux.

\section{Ruído}

O ruído foi medido durante toda a jornada de trabalho sem atrapalhar no decorrer natural da atividade. Desta forma, por se tratar de uma fábrica de produção de ferramentas por forjamento ocorriam ruído de impacto e ruído contínuo. Como a mensuração dos níveis de ruído aconteceu com várias máquinas atuando no mesmo local, os níveis de ruído foram tomados como ruído contínuo, com o uso de um decibelímetro digital, no circuito de resposta lenta (slow) e curva de ponderação "A", com sensor posicionado próximo ao ouvido do trabalhador, enquanto operava a máquina (NR 15).

A FUNDACENTRO NHO 01 (2001) recomenda que aparelhos de medição instantânea, não fixados no operador, poderão ser utilizados na avaliação de determinadas situações de exposição operacional. Foi escolhido por permitir medições no operador em cada máquina utilizada no processo de produção de ferramentas.

Os limites de tolerância para ruído contínuo ou intermitente devem obedecer a NR-15 (NORMA REGULAMENTADORA: NR 15, 2012). O limite máximo para uma jornada de 8 horas deve ser de 85 $\mathrm{dB}(\mathrm{A})$. A cada $5 \mathrm{~dB}(\mathrm{~A})$ acrescidos aos níveis de ruído deve-se reduzir a jornada de trabalho à metade da exposição diária permitida ou proteger o trabalhador.

\section{Procedimento estatístico}

Inicialmente, fez-se um estudo-piloto para definir o tamanho mínimo das amostras dos dados a serem utilizados na pesquisa. Esses dados foram analisados por meio da Equação 2 proposta por Conaw (1977).

$$
n>\frac{t^{2} s^{2}}{e^{2}}
$$

Em que: $n=$ número mínimo de amostras necessárias; $t$ = valor tabelado a $10 \%$ de probabilidade (distribuição $\mathrm{t}$ de Student); $s=$ desvio padrão da amostra; e $e=$ erro admissível a $10 \%$ em torno da média.

Os resultados obtidos dos níveis de conforto térmico, ventilação, iluminação e ruído, foram submetidos a uma análise de variância no delineamento inteiramente casualizado. As médias que apresentaram diferenças estatísticas significativas foram comparadas pelo teste de Tukey, a 10\% de probabilidade.

\section{RESULTADOS E DISCUSSÃO}

\section{Procedimento estatístico}

Para caracterizar o ambiente de trabalho na fábrica de produção de ferramentas foram coletadas 200 amostras para cada variável em estudo: conforto térmico, ventilação, iluminância e ruído. Desta forma, foi respeitado o número mínimo tendo representatividade amostral. A estatística descritiva e número mínimo de amostras necessárias para o ambiente de trabalho de produção de ferramentas são apresentados na Tabela 3 . 
TABELA 3: Estatística descritiva e número mínimo de amostras para as variáveis do ambiente de trabalho de produção de ferramentas.

TABLE 3: Descriptive statistics and minimum number to work environment variables of the tool production.

\begin{tabular}{ccccccccccccc}
\hline & & EV & TE & ES & F1 & F2 & VI & OR & C1 & C2 & SO & IC \\
\hline Conforto & $\left({ }^{\circ} \mathrm{C}\right)^{\mathrm{x}}$ & 23,8 & 24,3 & 24,5 & 25,6 & 25,2 & 24,4 & 24,2 & 23,7 & 23,6 & 23,8 & 24,2 \\
térmico & $\mathrm{S}$ & 1,7 & 2,1 & 1,6 & 1,8 & 1,7 & 1,5 & 1,5 & 1,4 & 1,4 & 1,6 & 1,7 \\
& Mín. & 1,5 & 2,1 & 1,2 & 1,4 & 1,2 & 1 & 1,1 & 1 & 1 & 1,3 & 1,3 \\
\hline \multirow{2}{*}{ Ventilação } & $(\mathrm{m} / \mathrm{s})^{\mathrm{x}}$ & 0,4 & 0,4 & 0,4 & 0,4 & 0,4 & 0,5 & 0,4 & 0,4 & 0,5 & 0,2 & 0,4 \\
& $\mathrm{~S}$ & 0,3 & 0,3 & 0,3 & 0,2 & 0,3 & 0,2 & 0,2 & 0,3 & 0,3 & 0,2 & 0,3 \\
& Mín. & 156,4 & 98 & 123,7 & 92,1 & 70,9 & 77 & 91,4 & 98,1 & 121 & 197 & 130,9 \\
\hline \multirow{2}{*}{ Iluminância } & $(\mathrm{lux})^{\mathrm{x}}$ & 98,2 & 83,3 & 117,2 & 66,6 & 71,8 & 103,4 & 151,5 & 252,7 & 322,8 & 171,8 & 117,8 \\
& $\mathrm{~S}$ & 36 & 37,1 & 81,4 & 35,7 & 34,6 & 51,3 & 64,8 & 99,7 & 109,8 & 118,9 & 53,3 \\
& Mín. & 36,2 & 53,6 & 130,6 & 77,9 & 62,9 & 66,5 & 49,5 & 42,1 & 31,3 & 129,7 & 55,4 \\
\hline \multirow{2}{*}{ Ruído } & $(\mathrm{dB}(\mathrm{A}))^{\mathrm{x}}$ & 83,6 & 89,9 & 94,2 & 91,3 & 93,6 & 87,6 & 86,6 & 86,5 & 85,4 & 86,8 & 90,9 \\
& $\mathrm{~S}$ & 4,7 & 4,3 & 3,2 & 1,9 & 2,8 & 1,8 & 1,7 & 2,4 & 1,6 & 1,5 & 2 \\
\hline
\end{tabular}

Em que: $\quad \mathrm{x}^{-}=$média; $S=$ desvio padrão; Mín = número mínimo de amostras necessárias, com a utilização de um " $\mathrm{t}$ " tabelado de 1,7 segundo tabela de Student. $E V=$ envernizamento, $T E=$ têmpera, $E S=$ esmeril, $F 1=$ forjadora $1, \mathrm{~F} 2=$ forjadora 2, $V I=$ viragem, $O R=$ orvado, $C 1=$ corte $1, C 2=$ corte $2, S O=$ soldagem; $I C=$ inserção de cabos.

As análises de conforto térmico e ruído, por possuírem baixa amplitude, apresentaram a necessidade de menor número de amostras quando comparadas às variáveis de ventilação e iluminância.

A ventilação foi a variável com maior intensidade amostral, em decorrência dos valores de ventilação baixos (recomendados abaixo de $0,7 \mathrm{~m} / \mathrm{s}$ ). Ao se utilizar a Equação de Conaw, o erro é multiplicado por uma média menor do que um, elevando-se, assim, o número mínimo de amostras.

\section{Conforto térmico}

Os valores relativos às condições climáticas, obtidos com IBUTG nas diferentes atividades da fabricação de ferramentas no decorrer da jornada de trabalho (por hora), são apresentados na Figura 1. 


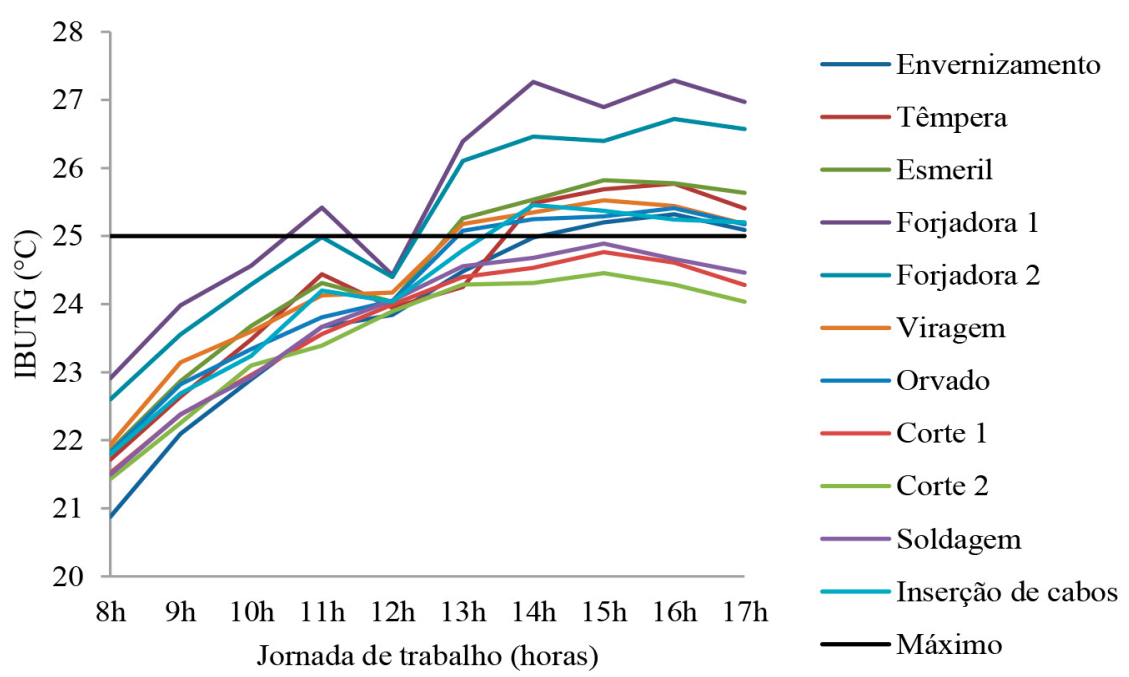

FIGURA 1: Conforto térmico durante a jornada de trabalho.

FIGURE 1: Thermal comfort during the workday.

A produção de ferramentas por forjamento é uma atividade classificada como pesada, pois o trabalho é intermitente de levantar, empurrar ou arrastar pesos de acordo com a NR-15 - ANEXO 3 (NORMA REGULAMENTADORA: NR 15, 2012). Com uma jornada de trabalho realizada continuamente nessas condições, deve-se ter um ambiente com um IBUTG de até $25^{\circ} \mathrm{C}$.

A Figura 1 mostra que a atividade de produção de ferramentas levou a uma tendência de crescimento no IBUTG. Os dados de IBUTG variaram em média de $20,9^{\circ} \mathrm{C}$ a $27,3^{\circ} \mathrm{C}$. Vale destacar que os dados foram coletados no verão, período mais quente do ano e, mesmo assim, a atividade se faz em conforto térmico em todas as atividades durante o período matutino e algumas atividades do período vespertino (corte 1 e 2 e soldagem).

No período vespertino, as atividades de produção de ferramentas não devem ser feitas continuamente, por extrapolarem o IBUTG recomendado.

No início da atividade, às $8 \mathrm{~h}$ da manhã, os trabalhadores estão expostos entre IBUTG de $20,9^{\circ} \mathrm{C}$ a $22,9^{\circ} \mathrm{C}$, para o envernizamento e esmeril, respectivamente, valores estes abaixo do índice máximo permitido pela NR-15.

Os valores de IBUTG a partir de $11 \mathrm{~h}$ do dia, na forjadora, foi de $25,4^{\circ} \mathrm{C}$. Com isso, é necessário trabalhar 45 minutos e fazer pausa de 15 minutos por hora.

Ao meio-dia, com os trabalhadores em seu período de almoço, em que as máquinas estão desligadas, os fornos apagados, ventiladores desligados, os dados de IBUTG sofreram uma redução e uma pequena queda na tendência de crescimento (Figura 1), principalmente na têmpera, esmeril, forjadora e inserção de cabos.

Às $13 \mathrm{~h}$, nas atividades do esmeril, viragem e orvado deve-se trabalhar por 45 minutos e descansar por 15 minutos por hora ou haver revezamento de atividade. Nas forjadoras é necessário trabalhar por 30 minutos e descansar por 30 minutos por hora para que o corpo se recupere da sensação de desconforto térmico. Em torno das $14 \mathrm{~h}$, o tempo de trabalho e descanso nas atividades de produção de ferramentas se comporta da mesma forma que às $13 \mathrm{~h}$, começando os trabalhadores da têmpera e inserção de cabos a trabalhar por 45 minutos e descansar por 15 minutos.

Das 15 às $17 \mathrm{~h}$, as atividades se comportam de forma semelhante no envernizamento, na têmpera, no esmeril, na viragem, no orvado e na inserção de cabos, devendo trabalhar por 45 minutos e pausar 15 minutos. Na forjadora, deve-se trabalhar por 30 minutos e pausar ou revezar por 30 minutos.

Nas atividades de soldagem e corte o trabalho se procede com conforto térmico durante toda jornada 
e pode ser executada continuamente.

Em estudos de conforto térmico em marcenarias no Distrito Federal, Fiedler, Venturoli e Minetti (2006) encontraram um IBUTG de $21,4^{\circ} \mathrm{C}$, que é perfeitamente tolerado para $8 \mathrm{~h}$ de trabalho. Da mesma forma, Fiedler et al. (2010) encontraram um IBUTG de $26,4^{\circ} \mathrm{C}$ para este tipo de atividade considerada moderada em marcenarias do sul do Estado do Espírito Santo, sendo aceitável até $26,7^{\circ} \mathrm{C}$.

Em um estudo de caso em uma indústria metalúrgica em Santa Cruz do Sul-RS, os setores de trabalho foram divididos em quatorze atividades e procedeu-se à análise quanto ao conforto térmico por meio do IBUTG, apresentando valores de 23,0 a $25,3^{\circ} \mathrm{C}$, pela NR-15 seria tolerado até $26,7^{\circ} \mathrm{C}$ (BARBIERO, 2004).

A Tabela 4 indica o IBUTG por hora para cada atividade do processo de produção de ferramentas e as comparações pelo teste de Tukey.

TABELA 4: Análise do conforto térmico $\left({ }^{\circ} \mathrm{C}\right)$ no processo de produção de ferramentas.

TABLE 4: Analysis of thermal comfort $\left({ }^{\circ} \mathrm{C}\right)$ of the production process tools.

\begin{tabular}{|c|c|c|c|c|c|c|c|c|c|c|}
\hline & h & $\mathrm{h}$ & $\mathrm{h}$ & $11 \mathrm{~h}$ & $2 \mathrm{~h}$ & $13 \mathrm{~h}$ & $14 \mathrm{~h}$ & $15 \mathrm{~h}$ & $16 \mathrm{~h}$ & 111 \\
\hline 1 & 3 & 24 & 5 & 5 & 4 & $6 \quad \mathrm{a}$ & $27 \quad \mathrm{a}$ & 27 & 27 & 27 \\
\hline & & & 24 & 25 & & & 27 & & 21 & 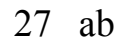 \\
\hline & & & & 24 & & & J & & & \\
\hline & & & 21 & 24 & & & $26 \mathrm{bc}$ & 2 & & \\
\hline & & & & 4 & & & & & & \\
\hline & & & 23 & 24 & & & & & & \\
\hline & c & & 24 & 2 & 24 & 24 & 26 & 26 & 26 & \\
\hline & & & 23 & 24 & 24 & 25 & 25 & 25 & & 24 \\
\hline & 22 & & 23 & 24 & 24 & $25 \mathrm{abc}$ & 25 & 25 & 25 & 25 \\
\hline & $\mathrm{d}$ & 22 & 23 & 24 & & 25 & 24 & 25 & 24 & 24 \\
\hline V & $1 \mathrm{~d}$ & a & 23 & 24 & 24 & 25 & 25 & 25 & & \\
\hline
\end{tabular}

Em que: Em que: $E V=$ envernizamento, $T E=$ têmpera, $E S=$ esmeril, $F 1=$ forjadora $1, F 2=$ forjadora $2, V I=$ viragem, $O R=$ orvado, $C 1=$ corte $1, C 2=$ corte $2, S O=$ soldagem; $I C=$ inserção de cabos. Médias seguidas por uma mesma letra, em coluna, não diferem a $10 \%$ de significância pelo teste de Tukey.

A região montanhosa na qual se encontra o galpão de produção facilitou manter o IBUTG em níveis toleráveis pela manhã. Os níveis de IBUTG em média, por atividade, só excederam o permitido pela NR-15 na forjadora 1 , às $11 \mathrm{~h}$ de manhã e a partir das $13 \mathrm{~h}$ nas forjadoras $1 \mathrm{e} 2$.

Às 8 e $11 \mathrm{~h}$, as atividades de maior IBUTG foram as forjadoras que não diferenciaram a $10 \%$ de significância pelo teste de Tukey. Em contrapartida, as menores médias estatisticamente semelhantes de IBUTG foram nas áreas de corte, soldagem e envernizamento no período das 8 às $9 \mathrm{~h}$. No intervalo das 10 às $11 \mathrm{~h}$, não houve diferença nos menores valores de IBUTG para a viragem, o orvado, a inserção de cabos, a têmpera, nas áreas de corte, a soldagem e o envernizamento.

Ao meio-dia, devido ao período de almoço, em que as máquinas estão desligadas, fornos apagados e ventiladores desligados, as médias de IBUTG não diferiram entre si para as atividades consideradas no estudo.

A partir das $13 \mathrm{~h}$, as atividades das forjadoras, de viragem, do esmeril, do orvado e da inserção de cabos não diferenciaram entre si em média e, dessa forma, apresentaram estatisticamente os maiores IBUTG. Já os menores IBUTG, em média, ficaram na viragem, no esmeril, no orvado, na inserção de cabos, na têmpera, nas áreas de corte, na soldagem e no envernizamento.

No período das 14 às $17 \mathrm{~h}$, houve resultado parecido com o apresentado no período das 8 às 9 $\mathrm{h}$ com a área das forjadoras, tendo os maiores valores de IBUTG. O orvado, áreas de corte, soldagem e envernizamento apresentaram estatisticamente os menores valores às $14 \mathrm{~h}$. No intervalo entre 15 às $17 \mathrm{~h}$, os menores valores foram observados nas atividades de viragem, do orvado, da inserção de cabos, das áreas de 
corte, da soldagem e do envernizamento.

O ideal seria dispor de um galpão aclimatado e que estivesse com a mesma temperatura em todas as atividades, mas, devido ao uso de ventiladores e presença de fornos para aquecimento das ferramentas houve grandes variações no IBUTG. Uma sugestão para melhoria das condições de trabalho é atuar na jornada de trabalho, priorizando a atividade em horas com IBUTG mais amenos.

\section{Ventilação}

A Figura 2 indica a velocidade média do vento $(\mathrm{m} / \mathrm{s})$ para as atividades de produção de ferramentas por hora durante a jornada de trabalho.

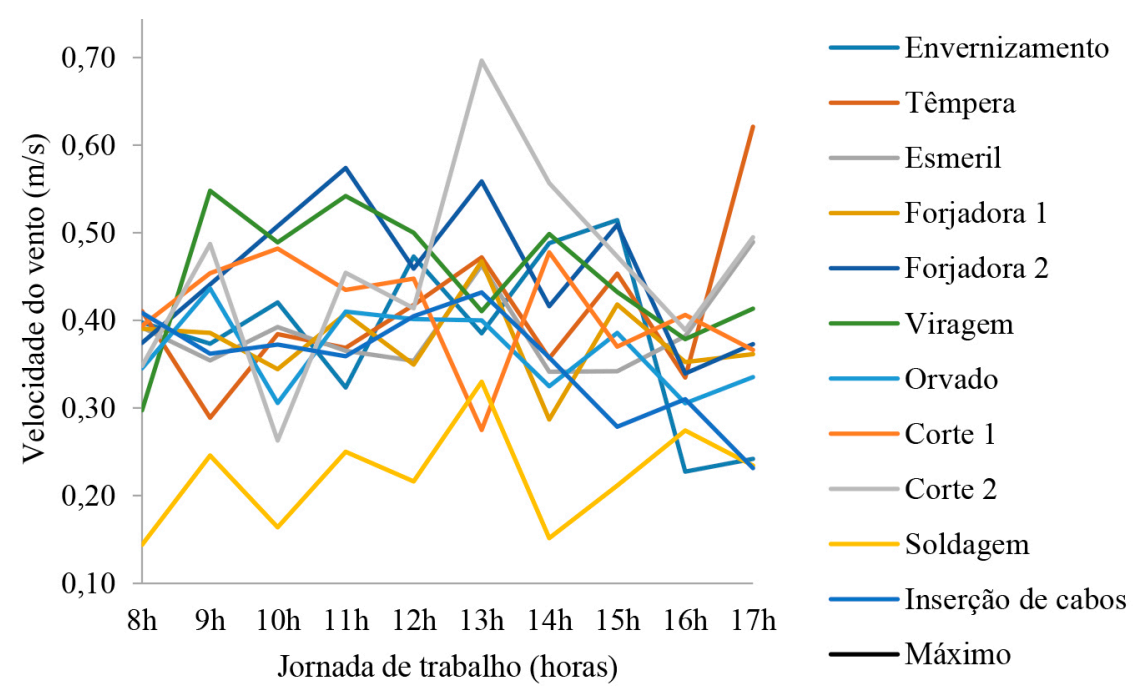

FIGURA 2: Velocidade média do vento durante a jornada de trabalho.

FIGURE 2: Average wind speed during the workday.

A velocidade do vento para todas as atividades dentro do galpão de produção de ferramentas não mostrou um padrão ou tendência, variando em média de $0,1 \mathrm{~m} / \mathrm{s}$ (soldagem às 8 horas) a $0,7 \mathrm{~m} / \mathrm{s}$ (corte 2 às $13 \mathrm{~h}$ ). Todas as atividades apresentaram velocidade do vento abaixo de $0,75 \mathrm{~m} / \mathrm{s}$, sendo perfeitamente aceitável durante toda jornada de trabalho pela NR-17.

Os mecanismos de ventilação, assumem importante destaque dentre os fatores do ambiente de trabalho, pois possuem riscos ocupacionais relacionados a ele, como a fragmentação de materiais particulados, que dependendo das suas dimensões podem ser aspirados pelos trabalhadores (LIED, 2011).

A Tabela 5 indica a velocidade do vento $(\mathrm{m} / \mathrm{s})$ por hora para cada atividade do processo de produção de ferramentas e as comparações pelo teste de Tukey. 
TABELA 5: Análise da velocidade do vento $(\mathrm{m} / \mathrm{s})$ no processo de produção de ferramentas.

TABLE 5: Analysis of the wind speed $(\mathrm{m} / \mathrm{s})$ in the process of tool production.

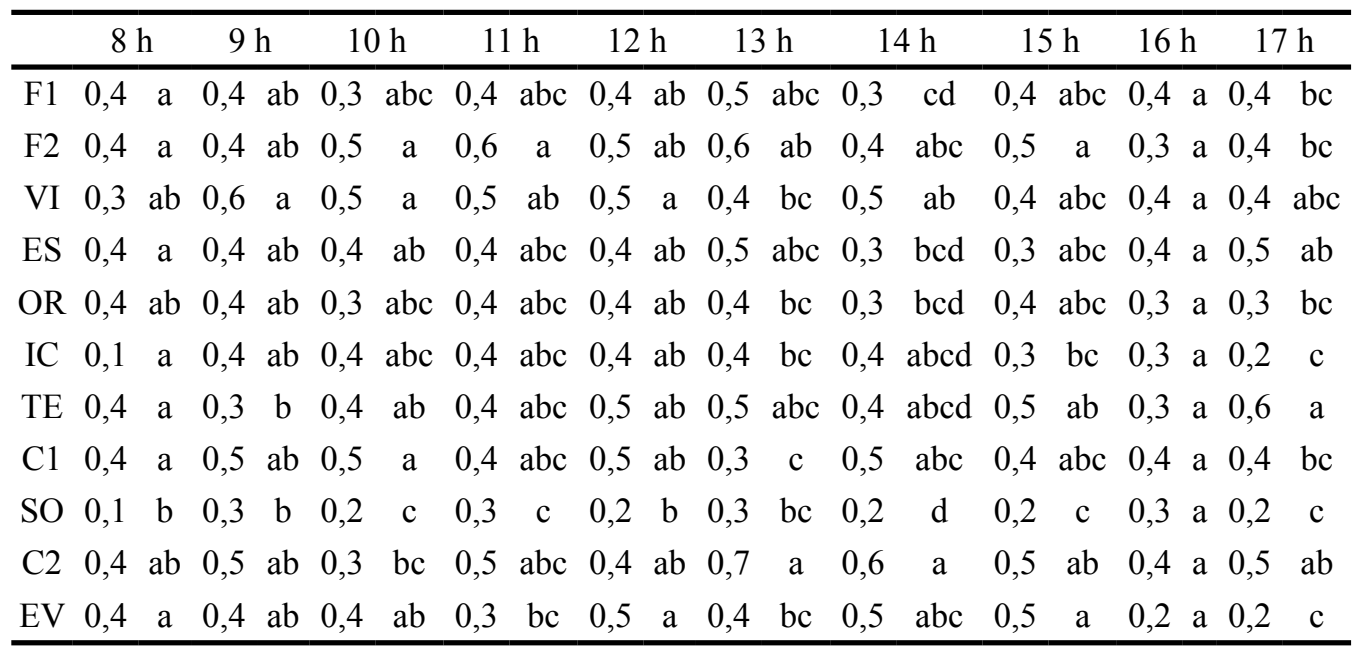

Em que: $\mathrm{EV}=$ envernizamento, $\mathrm{TE}=$ têmpera, $\mathrm{ES}=$ esmeril, $\mathrm{F} 1=$ forjadora $1, \mathrm{~F} 2=$ forjadora $2, \mathrm{VI}=$ viragem, $\mathrm{OR}=$ orvado, $\mathrm{C} 1$ = corte $1, \mathrm{C} 2$ = corte $2, \mathrm{SO}=$ soldagem; $\mathrm{IC}=$ inserção de cabos. Médias seguidas por uma mesma letra, em coluna, não diferem a $10 \%$ de significância pelo teste de Tukey.

As comparações da velocidade do vento, pelo teste de Tukey a 10\% de significância (Tabela 6), mostraram que não houve um predomínio do vento em uma área específica do galpão de produção de ferramentas, durante a jornada de trabalho.

Pela manhã, as atividades com menores médias de velocidade do vento se encontraram: no orvado, soldagem e corte 2 . Na parte da tarde (13 às $17 \mathrm{~h}$ ), além das regiões anteriores, acrescentam-se a forjadora 1 e a inserção de cabos. Mesmo não ultrapassando os limites permissíveis de velocidade do vento é necessário que haja uma velocidade do vento constante e uniforme, principalmente na soldagem e esmeril, para remoção do ar contaminado por resíduos do processo produtivo.

Às $16 \mathrm{~h}$, não houve diferença mínima significativa entre as atividades. No entanto, durante toda a jornada de trabalho não se excedeu o limite recomendado pela NR-17.

\section{Iluminância}

Os níveis médios de iluminância ao longo da jornada de trabalho para as atividades de produção de ferramentas são mostrados na Figura 3. 

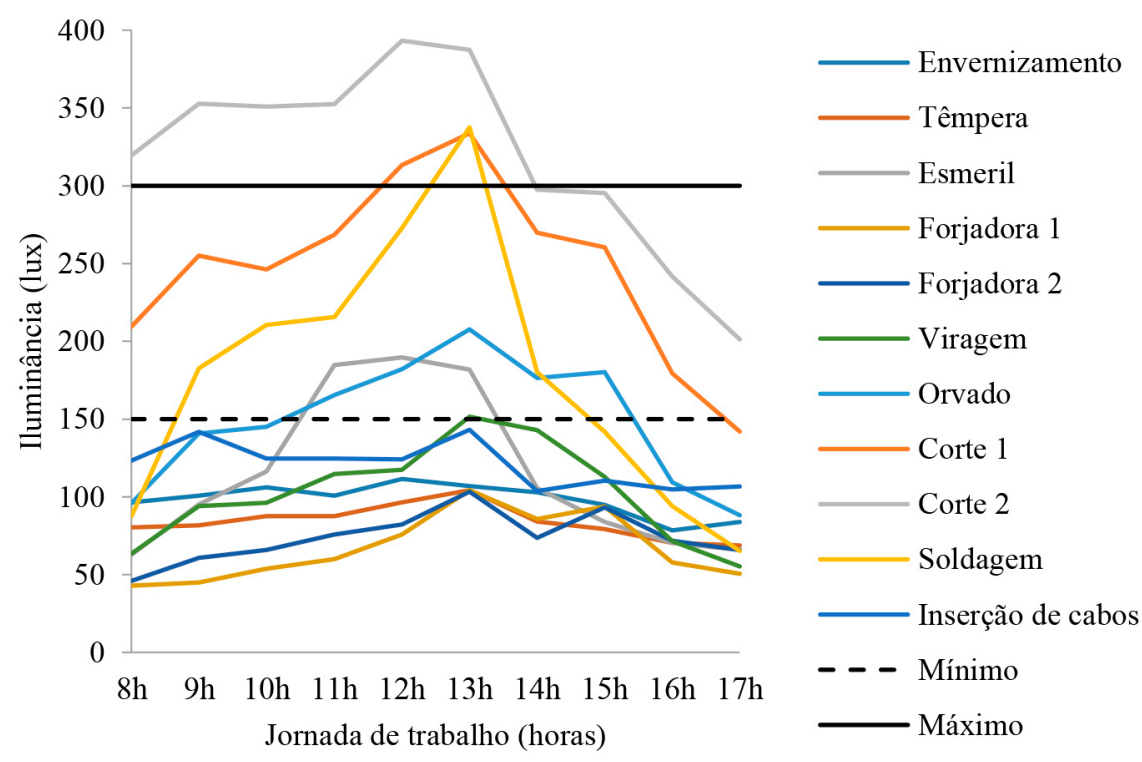

FIGURA 3: Iluminância média durante a jornada de trabalho.

FIGURE 3: Average illuminance during the workday.

Os maiores níveis de iluminância se concentraram das 11 às $14 \mathrm{~h}$. Todas as atividades apresentaram um aumento em iluminância das 8 às $13 \mathrm{~h}$ e um decréscimo das 13 às $17 \mathrm{~h}$. Isso se explica pela variação da luz solar ao longo do dia no galpão de produção. As atividades que se localizam na periferia do galpão apresentaram uma variação maior de iluminância, assim como as regiões que se encontram ao centro do galpão possuem uma menor quantidade de iluminância.

Utilizando os limites de iluminância descritos na ABNT NBR 5413 (1992), para usinas de aço que trabalham com forjadoras e salas de máquinas, é necessário entre 150 e 300 lux.

As atividades de soldagem e áreas de corte por se localizarem na periferia do galpão apresentaram maiores variações na quantidade de luz durante a jornada de trabalho, não têm incidência direta da luz natural, mas possuem um aumento ou diminuição da quantidade de luz proporcionais à movimentação do sol sobre o galpão de produção.

As atividades de envernizamento, têmpera, forjadoras e inserção de cabos apresentaram médias de iluminância abaixo do necessário (150 lux) durante toda a jornada de trabalho.

Poucas foram as atividades que possuíam iluminância de 150 a 300 lux: esmeril das 11 às $13 \mathrm{~h}$, viragem às $13 \mathrm{~h}$, orvado das 11 às $15 \mathrm{~h}$, corte 1 das 8 às $11 \mathrm{~h}$ e 14 às $17 \mathrm{~h}$, corte 2 das 14 às $17 \mathrm{~h}$ e soldagem das 8 às $12 \mathrm{~h}$ e às $14 \mathrm{~h}$. No entanto, não basta apenas ter uma média de iluminância dentro do aceitável, é preciso que esses níveis permaneçam constantes durante toda a jornada de trabalho. A Tabela 6 indica a iluminância (lux) por hora para cada atividade do processo de produção de ferramentas e as comparações pelo teste de Tukey. 
TABELA 6: Análise da iluminância (lux) no processo de produção de ferramentas.

TABLE 6: Analysis of illuminance (lux) in the process of tool production.

\begin{tabular}{|c|c|c|c|c|c|c|c|c|c|c|c|c|c|c|c|c|c|}
\hline \multicolumn{3}{|c|}{$8 \mathrm{~h}$} & \multicolumn{2}{|c|}{$\mathrm{h}$} & \multicolumn{2}{|c|}{$10 \mathrm{~h}$} & \multicolumn{2}{|c|}{$11 \mathrm{~h}$} & \multicolumn{2}{|c|}{$12 \mathrm{~h}$} & \multicolumn{2}{|c|}{$13 \mathrm{~h}$} & $14 \mathrm{~h}$ & \multicolumn{2}{|c|}{$15 \mathrm{~h}$} & \multicolumn{2}{|c|}{$16 \mathrm{~h} \quad 17 \mathrm{~h}$} \\
\hline 1 & 43 & & 4 & $\mathrm{f}$ & 53 & & 59 & $\mathrm{e}$ & 75 & $\mathrm{e}$ & 04 & d & $86 \mathrm{~d}$ & 94 & & $57 \mathrm{~d}$ & 50 \\
\hline 42 & 45 & & 59 & 1 & & ef & 71 & e & 77 & e & & & $72 \mathrm{~d}$ & 94 & & 12 & 66 \\
\hline & 34 & & 96 & $f$ & & 1 & & de & 119 & de & 154 & bcd & 140 & 114 & & 72 & 55 \\
\hline & & & 20 & & & & & 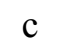 & 194 & $c$ & 186 & 00 & 107 & 84 & & 11 & 6 \\
\hline & & & & & & & & & & & 1 & b & $178 \mathrm{~b}$ & 184 & & 111 & 90 \\
\hline $\mathrm{C}$ & 25 & & 140 & cde & & & & & 11 & 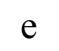 & 3 & $\mathrm{~cd}$ & 100 & 1 & & 105 & 109 \\
\hline$\Gamma E$ & 80 & & & ef & & & & 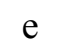 & 96 & e & 104 & $d$ & 83 & 79 & & 70 & 68 \\
\hline $\mathrm{C} 1$ & 215 & & 1 & b & 25 & & 274 & $\mathrm{~b}$ & 320 & b & 340 & $\mathrm{a}$ & 275 & 265 & & 183 & 145 \\
\hline $\mathrm{O}$ & 76 & & 4 & c & 20 & & 209 & $\mathrm{c}$ & 267 & b & 335 & a & 174 & 134 & & 87 & 59 \\
\hline $\mathrm{C} 2$ & 325 & & 358 & $\mathrm{a}$ & 356 & $\mathrm{a}$ & 357 & $\mathrm{a}$ & 397 & $\mathrm{a}$ & 390 & $\mathrm{a}$ & 299 a & 297 & & 245 & 204 \\
\hline V & 96 & & 01 & of & 106 & & 101 & & 112 & 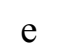 & 107 & $d$ & 103 & 95 & & 79 & 84 \\
\hline
\end{tabular}

Em que: $E V=$ envernizamento, $T E=$ têmpera, $E S=$ esmeril, $F 1=$ forjadora $1, F 2=$ forjadora 2, $V I=$ viragem, $O R=$ orvado, $C 1=$ corte $1, C 2=$ corte $2, S O=$ soldagem; $I C=$ inserção de cabos. Médias seguidas por uma mesma letra, em coluna, não diferem a $10 \%$ de significância pelo teste de Tukey.

De manhã (entre 8 e 12 h), a atividade de maior iluminância foi o corte 2. Como se localiza na extremidade do galpão, apresentou altos níveis de iluminamento. Nessa atividade deve-se tomar cuidado com ofuscamentos que podem ser causados pela presença da luz natural. A segunda maior iluminância e que merece atenção é o corte 1 e a soldagem no período matutino. Na parte da tarde (13 às $17 \mathrm{~h}$ ), essas três atividades apresentaram maiores valores de iluminância, que não diferiram entre si; às 14 e 15 horas, as área de corte apresentaram a maior média estatisticamente de iluminância; e às 16 e 17 h, o corte 2 apresentou o maior valor de iluminância.

A maioria das atividades apresentou valores baixos de iluminância, não atingindo o valor de 150,0 lux, podendo comprometer a eficiência da produção de ferramentas, uma vez que não favorece a rápida visualização de objetos e peças no processo produtivo.

No corte 1 , a quantidade de luz estava mais alta do que os 300 lux recomendados até às $14 \mathrm{~h}$, no corte 2 das 12 às $14 \mathrm{~h}$ e na soldagem durante o período do almoço (12 às $13 \mathrm{~h}$ ).

Com o objetivo de propor a adequação do layout de uma fábrica de ferramentas, Guimaraes et al. (2013) verificaram que a iluminância foi um dos itens do ambiente de trabalho que estavam abaixo dos níveis recomendados pela NR-15, aconselhando a otimização para uma melhor condição de trabalho.

\section{Ruído}

A Figura 4 indica os níveis médios de ruído durante a jornada de trabalho nas diferentes atividades do processo produtivo. 

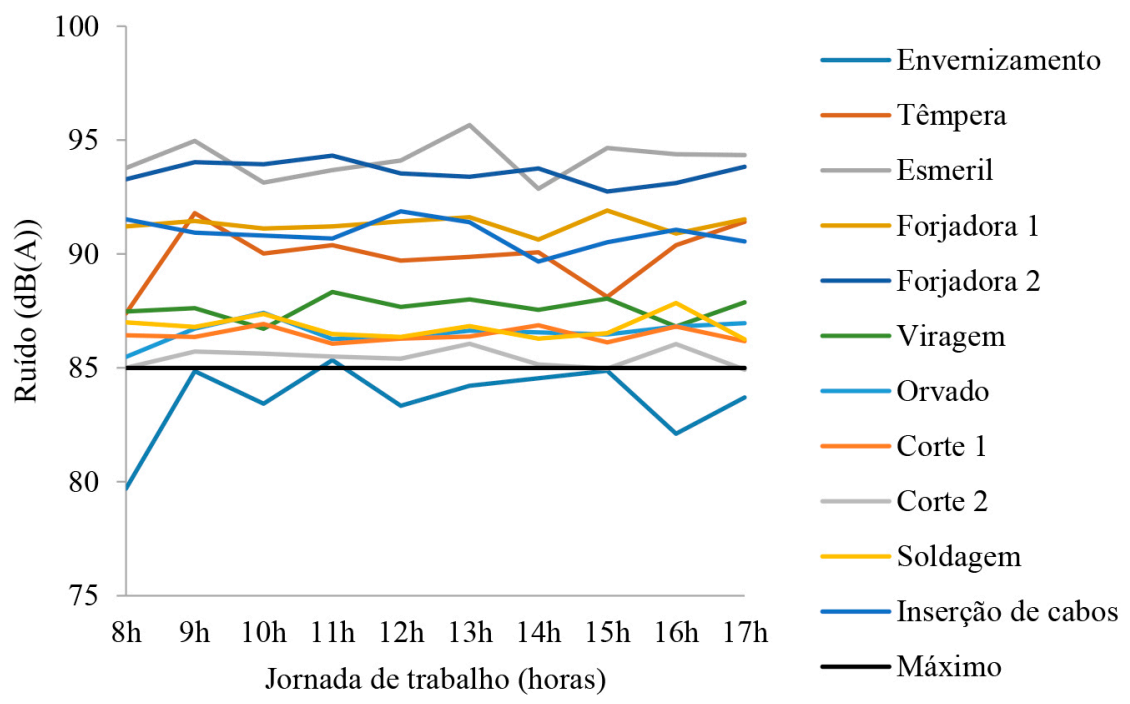

FIGURA 4: Ruído durante a jornada de trabalho.

FIGURE 4: Noise during the workday.

Segundo a NR-15, para uma jornada de trabalho de 8 horas diárias é permitido uma exposição ao ruído de até $85 \mathrm{~dB}(\mathrm{~A})$, sem a utilização de protetor auricular. A empresa exige que seus funcionários utilizem protetor auricular de concha ou de plugue.

As atividades não apresentaram variações bruscas para os níveis de ruído durante a jornada de trabalho (Figura 4). Os níveis de ruído variaram em média de 79,7 (envernizamento às 8 h) a 95,7 dB(A) (esmeril às $13 \mathrm{~h}$ ).

Apenas o envernizamento e o corte 1 apresentaram valores de ruído abaixo de $85 \mathrm{~dB}(\mathrm{~A})$. Todas as outras atividades estavam com médias de ruído acima do permitido durante toda a jornada de trabalho.

A Tabela 7 indica os níveis de ruído $(\mathrm{dB}(\mathrm{A}))$ por hora para cada atividade do processo de produção de ferramentas e as comparações pelo teste de Tukey.

TABELA 7: Análise do ruído (dB(A)) no processo de produção de ferramentas.

TABLE 7: Analysis of noise $(\mathrm{dB}(\mathrm{A})))$ in the process of tool production.

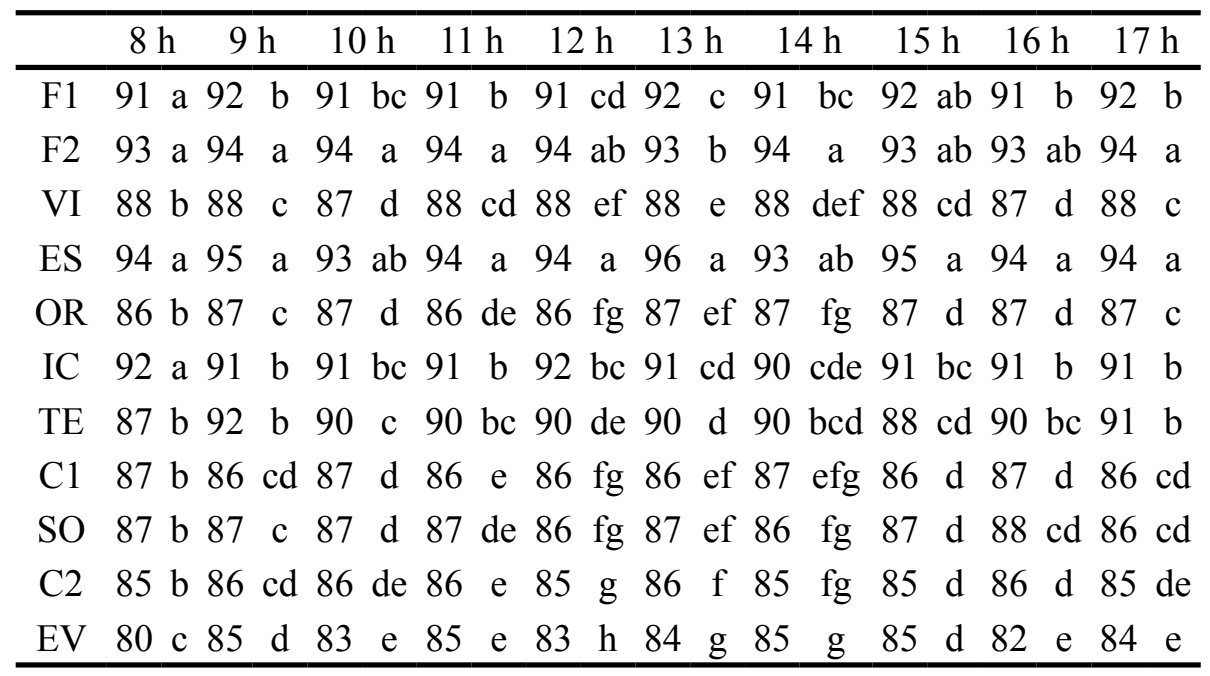

Em que: $E V=$ envernizamento, $T E=$ têmpera, $E S=$ esmeril, $F 1=$ forjadora $1, F 2=$ forjadora 2, $V I=$ viragem, $O R=$ orvado, $C 1=$ corte $1, C 2=$ corte 2, $S O=$ soldagem; $I C=$ inserção de cabos. Médias seguidas por uma mesma letra, em coluna, não diferem a $10 \%$ de significância pelo teste de Tukey. 
Nas atividades de corte, soldagem e viragem, os trabalhadores estavam expostos a mais de 85 $\mathrm{dB}(\mathrm{A})$, necessitando de medidas corretivas como o uso do protetor auricular para cumprir a jornada de trabalho de 8 horas diárias.

Na têmpera, inserção de cabos, áreas das forjadoras e esmeril, os trabalhadores estavam expostos a mais de $90 \mathrm{~dB}(\mathrm{~A})$, podendo trabalhar sem protetor auricular por apenas 4 horas diárias.

Para as atividades com ruído acima de $85 \mathrm{~dB}(\mathrm{~A})$ é necessário preferencialmente medidas preventivas para a redução do nível de exposição e caso não seja possível, a utilização de protetor auricular.

Os níveis de ruído se mostraram altos na produção de ferramentas. Em todas as atividades, em pelo menos uma hora por dia, apresentaram valores de ruído acima de $85 \mathrm{~dB}(\mathrm{~A})$. Durante toda a atividade, a forjadora 2 e o esmeril, apresentaram, em média, os maiores níveis de ruído.

Pelas comparações de ruído (teste de Tukey a 10\% de significância), encontraram-se as regiões com mesmos níveis de ruído (que não diferiram entre si) nas quais se devem tomar medidas conjuntamente para redução da exposição dos trabalhadores ao ruído nestas áreas. Por exemplo, das 9 às $12 \mathrm{~h}$, a forjadora 2 e o esmeril permaneceram estatisticamente com maiores níveis de ruído. Nestas áreas, deve-se adotar medidas preventivas ou promover uma rotatividade entre os trabalhadores para que se alternem atividades de menor exposição ao ruído.

O maior nível de ruído encontrado foi no esmeril às $13 \mathrm{~h}$, com $95,7 \mathrm{~dB}(\mathrm{~A})$, situação preocupante $\mathrm{e}$ que merece medidas preventivas e/ou corretivas urgentes. Para essa situação sem protetor auricular, poderse-ia expor o trabalhador a apenas $1,98 \mathrm{~h}$ de trabalho sem que haja danos ao sistema auditivo.

\section{CONCLUSÕES E RECOMENDAÇÕES}

O processo de fabricação de ferramentas discorre com conforto térmico na parte da manhã, exceto na forjadora 1 às $11 \mathrm{~h}$. À tarde, apresentaram valores acima de $25^{\circ} \mathrm{C}$ em pelo menos uma atividade por hora, necessitando-se de repouso ou rodízio;

As áreas das forjadoras apresentaram os maiores índices de IBUTG, em média, durante o processo produtivo, caracterizando desconforto térmico;

A velocidade do vento não apresentou uma tendência de crescimento e todas as atividades apresentaram velocidade do vento abaixo de $0,75 \mathrm{~m} / \mathrm{s}$, toleráveis para a condição de trabalho;

Poucas foram as atividades que apresentaram valores de iluminância dentro do limite recomendado. Desta forma, a iluminação foi considerada deficiente em grande parte das atividades, necessitando de medidas emergenciais de controle;

De acordo com a NR 15, apenas o envernizamento e o corte 1 apresentaram níveis de ruído dentro do recomendado. Todas as outras atividades estavam com média de ruído acima do permitido durante toda a jornada de trabalho, necessitando de reorganização.

Aumentar o período de pausas de acordo com os dados de conforto térmico, para que os trabalhadores possam promover um descanso e, dessa forma, ficarem menos acometidos a dores após a jornada de trabalho;

Realizar rodízio entre as atividades de menor conforto térmico;

Aumentar o beiral do telhado para reduzir a incidência direta da radiação solar que eleva os níveis de iluminância das máquinas posicionadas na periferia do galpão;

Aumentar os pontos de iluminância dentro do galpão nas regiões de menor iluminância. E, se ainda sim permanecer a baixa iluminância, adotar a iluminação específica sobre a atividade;

Quando for realizar novas aquisições de máquinas, dar preferência a máquinas com menor emissão de ruído com a substituição de superfícies metálicas por absorvedoras e engrenagens de correntes a correias;

Melhorar as manutenções preventivas e corretivas das máquinas já existentes para redução do ruído emitido. 


\section{REFERÊNCIAS}

AGÊNCIA NACIONAL DE ÁGUAS. Região hidrográfica Atlântico Sudeste. 2010. Disponível em: $<$ www2.ana.gov.br>. Acesso em: 28 dez. 2010.

ASSOCIAÇÃO BRASILEIRA DE NORMAS TÉCNICAS. NBR 5413: iluminância de interiores. Rio de Janeiro, 1992. 13 p.

ASSOCIAÇÃO BRASILEIRA DE NORMAS TÉCNICAS. NBR ISO 8995: iluminação de ambientes de trabalho. Rio de Janeiro, 2013. 46 p.

BARBIERO, M. Avaliação das percepções quanto ao ambiente de térmico em uma indústria metalúrgica: um estudo de caso. 2004. 139 f. Dissertação (Mestrado em Engenharia) - Universidade Federal do Rio Grande do Sul, Porto Alegre, 2004.

CONAW, P. L. Estatística. São Paulo: Edgard Blucher, 1977. 264 p.

COUTO, H. A. Ergonomia aplicada ao trabalho: manual técnico da máquina humana. Belo Horizonte: Ergo, 1995. 353 p.

DUTRA, T. R.; LEITE, A. M. P.; MASSAD, M. D. Avaliação de fatores do ambiente de trabalho em atividades de um viveiro florestal de Curvelo, Minas Gerais. Floresta, Curitiba, v. 42, n. 2, p. 269-276, 2012.

FIEDLER, N. C. et al. Avaliação ergonômica do ambiente de trabalho em marcenarias no sul do Espírito Santo. Revista Árvore, Viçosa, MG, v. 34, p. 907-915, 2010.

FIEDLER, N. C. et al. Influência da massa específica aparente da madeira no ruído produzido durante o processamento secundário: estudo de caso. Floresta, Curitiba, v. 39, n. 2, p. 401-408, 2009 a.

FIEDLER, N. C. et al. Otimização do layout de marcenarias no Sul do Espírito Santo baseado em parâmetros ergonômicos e de produtividade. Revista Árvore, Viçosa, MG, v. 33, n. 1, p. 161-170, $2009 \mathrm{~b}$.

FIEDLER, N. C.; VENTUROLI, F.; MINETTI, L. J. Análise de fatores ambientais em marcenarias no Distrito Federal. Revista Brasileira de Engenharia Agrícola e Ambiental, Campina Grande, v. 10, n. 3, p. 679-685, 2006.

FILIPE, A. P. et al. Avaliação de ruído em fábrica de móveis. Cerne, Lavras, v. 20, n. 4, p. 551-556, 2014. FUNDACENTRO. NHO 01. Norma de Higiene Ocupacional 01. Procedimento Técnico. Avaliação da Exposição Ocupacional ao Ruído. FUNDACENTRO, 2001.

GUIMARAES, P. P. et al. Adequação do layout de uma fábrica de ferramentas florestais baseado em parâmetros ergonômicos. Floresta, Curitiba, v. 43, n. 4, p. 515-524, 2013.

IIDA, I. Ergonomia: projeto e produção. 3. ed. rev. e ampl. São Paulo: Edgard Blücher, 2016.

LIED, E. B. Dimensionamento de sistema de ventilação local exaustora (VLE): estudo de caso de uma indústria de móveis, em Santa Terezinha de Itaipu, PR, Brasil. Estudos Tecnológicos em Engenharia, São Leopoldo, v. 1, n. 1, p.1-11, 2011.

NORMA REGULAMENTADORA: NR 15. Atividades e operações insalubres. In: Segurança e medicina do trabalho. $70^{a}$. ed. São Paulo: Atlas, 2012. p. 227-309.

NORMA REGULAMENTADORA: NR 17. Ergonomia. In: Segurança e medicina do trabalho. 70. ed. São Paulo: Atlas, 2007. p. 321-334.

MANUAIS DE LEGISLAÇÃO. Segurança e medicina do trabalho. $70^{\mathrm{a}}$. ed. São Paulo: Atlas, 2012. 799 p.

VILLAROUCO, V;; ANDRETO, L. F. M. Avaliando desempenho de espaços de trabalho sob o enfoque da ergonomia do ambiente construído. Produção, São Paulo, v. 18, n. 3, p. 523-539, set./dez. 2008. 